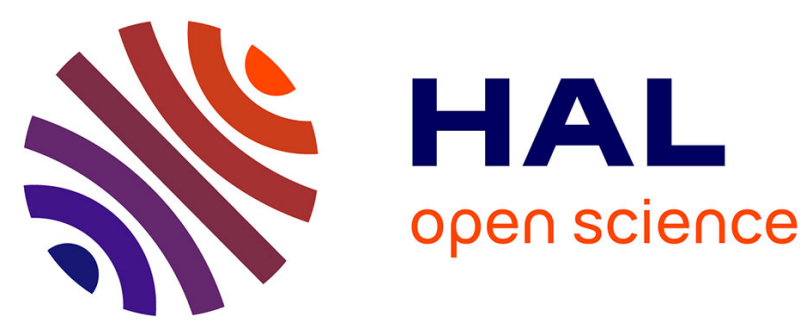

\title{
Bragg gratings and Fabry-Perot interferometers on an Er-MgO-doped optical fiber
}

Tiago Paixão, Luis Pereira, Rui Min, Carlo Molardi, Wilfried Blanc, Daniele Tosi, Carlos Marques, Paulo Antunes

\section{- To cite this version:}

Tiago Paixão, Luis Pereira, Rui Min, Carlo Molardi, Wilfried Blanc, et al.. Bragg gratings and FabryPerot interferometers on an Er-MgO-doped optical fiber. Optics and Laser Technology, 2020, 123, pp.105946. 10.1016/j.optlastec.2019.105946 . hal-02500099

\section{HAL Id: hal-02500099 \\ https://hal.science/hal-02500099}

Submitted on 5 Mar 2020

HAL is a multi-disciplinary open access archive for the deposit and dissemination of scientific research documents, whether they are published or not. The documents may come from teaching and research institutions in France or abroad, or from public or private research centers.
L'archive ouverte pluridisciplinaire HAL, est destinée au dépôt et à la diffusion de documents scientifiques de niveau recherche, publiés ou non, émanant des établissements d'enseignement et de recherche français ou étrangers, des laboratoires publics ou privés. 


\title{
Bragg gratings and Fabry-Perot interferometers on an Er-MgO-doped optical fiber
}

\author{
Tiago Paixão ${ }^{\mathrm{a}, *}$, Luís Pereira ${ }^{\mathrm{a}}$, Rui Min ${ }^{\mathrm{b}}$, Carlo Molardi ${ }^{\mathrm{c}}$, Wilfried Blanc ${ }^{\mathrm{d}}$, Daniele Tosi ${ }^{\mathrm{c}, \mathrm{e}}$, \\ Carlos Marques ${ }^{\mathrm{a}}$, Paulo Antunes ${ }^{\mathrm{a}, \mathrm{f}}$ \\ ${ }^{a}$ I3N \& University of Aveiro, Physics Department, Aveiro, Portugal \\ ${ }^{\mathrm{b}}$ ITEAM Research Institute, Universitat Politècnica de València, València, Spain \\ ${ }^{c}$ Nazarbayev University, School of Engineering 010000 Nur-Sultan, Kazakhstan \\ ' INPHYNI-CNRS UMR Université Côte d'Azur, Nice, France \\ ${ }^{\mathrm{e}}$ Laboratory of Biosensors and Bioinstruments, National Laboratory Astana, 010000 Nur-Sultan, Kazakhstan \\ ${ }^{\mathrm{f}}$ Instituto de Telecomunicaçōes, Aveiro, Portugal
}

\section{H I G H L I G H T S}

- FBGs and FPIs inscribed in an Er-MgO doped optical fiber, by a femtosecond laser.

- High-performance on the inscription of FBGs (reflectivity of $\sim 99 \%$ ).

- Achieved sensitivities of $0.91 \mathrm{pm} / \mu \varepsilon$ and $12.7 \mathrm{pm} /{ }^{\circ} \mathrm{C}$.

- FBGs can sustain high temperatures up to $700^{\circ} \mathrm{C}$, without significant degradation.

\section{A R T I C L E I N F O}

\section{Keywords:}

Fiber bragg grating

Femtosecond Laser

Fabry-Pérot interferometer

Doped optical fiber

\begin{abstract}
A B S T R A C T
In this paper, the fabrication of fiber Bragg gratings (FBGs) and intrinsic Fabry-Pérot interferometers (IFPIs) on an Er-MgO-doped silica optical fiber is reported. The inscription of both sensing devices was performed by means of a femtosecond laser, using the phase mask method to inscribe the FBG and a micromachining platform for the IFPI. Thermal and strain characterizations were performed for both devices, achieving the maximum sensitivities of $12.57 \mathrm{pm} /{ }^{\circ} \mathrm{C}$ and $0.85 \mathrm{pm} / \mu \varepsilon$ for the FBG case, and $10.2 \mathrm{pm} /{ }^{\circ} \mathrm{C}$ and $0.91 \mathrm{pm} / \mu \varepsilon$ for the IFPI. A high temperature experiment was conducted to assess the thermal behavior of the inscribed FBG, revealing sensing capabilities for temperatures up to $700{ }^{\circ} \mathrm{C}$. The results confirm that this new type of fiber will have an important role on the development of new optoelectronic devices, such as fiber lasers, optical amplifiers and sensors.
\end{abstract}

\section{Introduction}

Doped optical fibers, especially rare earth (RE)-doped, have been widely used to develop both optical power amplifiers and lasers $[1,2]$. The telecommunications market and its high demands regarding power consumptions and performance, requires a continuous investigation and improvement of these optical fibers' absorption and optical amplification properties. One viable method widely reported, consists on embedding RE ions within oxide nanoparticles (NPs) [1]. This way, combining optical fibers intrinsic advantages, such as lightweight, small size, biocompatibility, immunity to electromagnetic interferences and passiveness, with RE/NP-doped optical fibers' features (controllable optical amplification, photo-sensitivity), new types of devices can be developed for a wide range of applications, not only in the telecommunications field, but also in sensing $[3,4]$.

Among all optical fiber sensors (OFSs) developed in the past few years, fiber Bragg gratings (FBGs) and Fabry-Pérot interferometers (FPIs) are the most common types. On one hand, FBGs are very attractive devices for sensing due to their unique advantages, such as multiplexing capability, easy fabrication method and possibility to work in reflection [5]. Even though their sensitivities to physical parameters (such as temperature and strain) are reproduceable and efficient for most applications, in some cases it is required higher sensitivity values. In these situations, FPIs emerge as a viable solution, once they can be fabricated to achieve much higher sensitivities than FBGs, either by extrinsic (EFPIs) or intrinsic (IFPIs) configurations (e.g. 
external cavities based on highly sensitive materials or sensitivity enhanced by Vernier effect, respectively [6,7]). However, with FPIs we lose the multiplexing capability, which in some cases is a critical factor. To overcome this issue, hybrid sensors based on both FPI and FBG have been reported $[8,9]$.

The inscription of FBGs and intrinsic Fabry-Pérot interferometers (IFPI) on RE/NP-doped optical fibers by typical UV laser techniques is not an easy task, mainly due to the absorption and/or reflection of the light by the dopants in the core region $[10,11]$. Moreover, commonly the attenuation factor of these fibers is very high, limiting its possible applications and making it difficult to simply insert them in the existing optical communication networks. One common approach to overcome these difficulties is to use a femtosecond laser (lasing at NIR region), which enables a fast inscription of structures inside the optical fibers, even when heavily doped with NPs [6,10-12].

NPs-doped optical fiber is a new-class of optical fibers with features that rely on the following fundamental challenging issues: fabrication process, light-matter interaction (light scattering, luminescence) and materials science (nucleation/growth and/or phase separation mechanisms). By controlling and fully understanding these processes, it will be possible to develop improved optoelectronic components and devices, such as fiber lasers, amplifiers, sensors, fiberscopes and light sources.

In this paper, we report on the fabrication of both FBG and IFPI on an Er-MgO-doped silica optical fiber. The inscription of both devices was conducted on a setup based on a NIR femtosecond laser, differing only on the fabrication method used: phase mask (FBG) and/or micromachining (IFPI). A thermal and strain characterization were performed on both devices, allowing to estimate the sensitivities for them both. Regarding the inscribed FBG, a high reflectivity of $\sim 99 \%$ was achieved, which allows it to work under temperatures as high as $700{ }^{\circ} \mathrm{C}$.

\section{Sensors' fabrication}

In this work, an Er-MgO-doped silica optical fiber is used to inscribe FBGs and IFPIs. The optical fiber was fabricated through a technique based on modified chemical vapor deposition (MCVD) and without the need of postceramming, which allows the embedding of rare earth ions within the in situ grown oxide nanoparticles (NPs) in silica-based preforms (for more fabrication details, see [1,13]). By controlling the $\mathrm{Mg}$ and $\mathrm{Er}^{3+}$ content, the scattering losses and optical attenuation values were minimized (see Table 1). The fabricated optical fiber has a cladding and core diameters of 125 and $8 \mu \mathrm{m}$, respectively.

For both devices' inscription, a femtosecond laser from Quantronix ( $\lambda=795 \mathrm{~nm}$, pulse width $\sim 130 \mathrm{fs}, \mathrm{f}=1 \mathrm{kHz}$ ) was used (Fig. 1(a)). The differences in the inscription setup are directly related to the fabrication methods used: phase mask (for FBG) and micromachining (for IFPI) (Fig. 1(b) and (c)). During the inscription, the transmission (FBG) and reflection (IFPI) spectra were recorded at ambient temperature by an OSA (Anritsu, model MS9740A and the light source from Amonics, model ALS-CL-17-B-FA) and an optical interrogator (Micron Optics, model SM125), respectively.

Before the inscriptions, two pieces of the doped optical fiber (approximately $5 \mathrm{~cm}$ ) were chemically stripped and cleaved at both ends. Then, two splices with SMF28E + were made at both sides of each doped-optical fiber pieces (splicing losses $<0.01 \mathrm{~dB}$ ).

Table 1

Er-MgO-doped optical fiber properties.

\begin{tabular}{lll}
\hline $\begin{array}{l}\text { Attenuation } \\
(\mathrm{dB} / \mathrm{m})\end{array}$ & Scattering gain $(\mathrm{dB})$ & Pol. Beat length $(\mathrm{cm})$ \\
\hline 2.6 & 2.0 & 13.0 \\
\hline
\end{tabular}
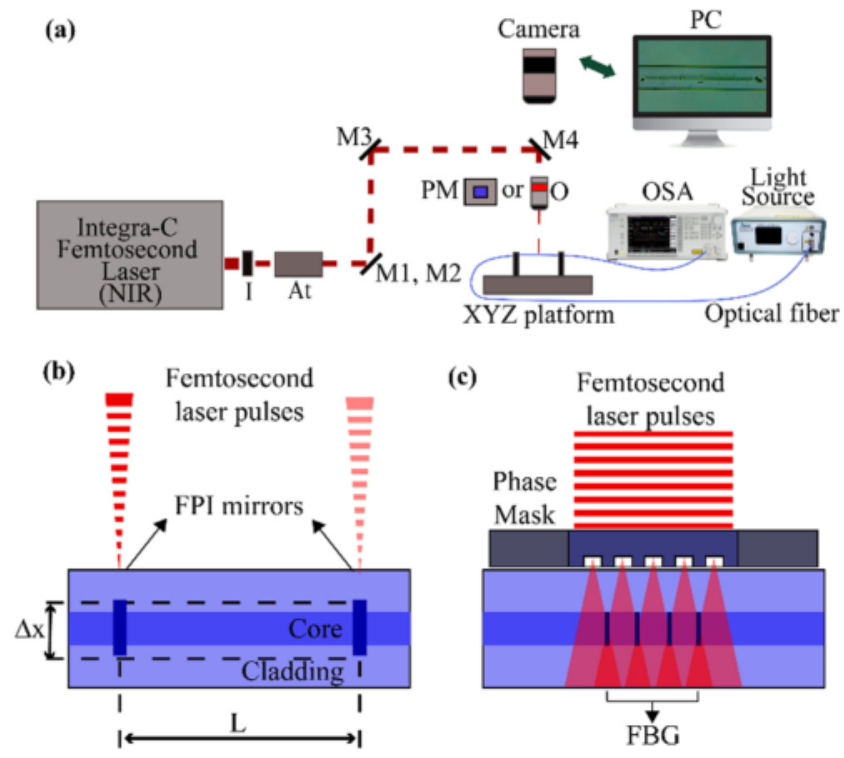

(d)

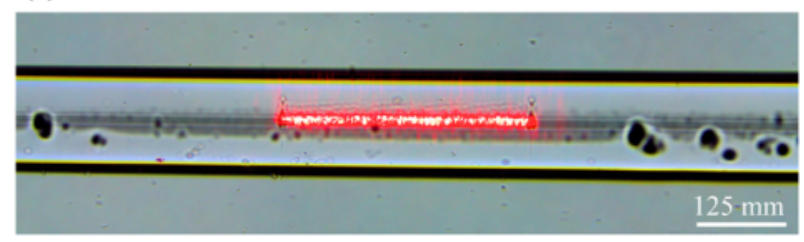

Fig. 1. (a) Schematic representation of the laser inscription setup used to fabricate both IFPI and FBG. I - iris, At - power attenuator, $\mathrm{M}$ - mirror, $\mathrm{O}-\mathrm{mi}$ croscope objective, PM - Phase mask, OSA - optical spectrum analyzer. In (b) and (c) the schematic representation of the FPI and FBG inscription methods are presented, respectively. (d) Microscope photograph of the IFPI illuminated by a red laser.

\subsection{Intrinsic Fabry-Pérot interferometer}

The fabrication of the IFPI was performed by using a 3-axis motorized translation platform, where a x 50 NIR microscope objective lens (with a NA value of 0.67 and a working distance of $10 \mathrm{~mm}$, from Optosigma) was used to focus the laser beam inside the optical fiber core. To assist and visualize at real time the IFPI inscription, a CCD camera was mounted on top of the setup, perpendicularly to the optical fiber and aligned with the laser beam.

To inscribe the IFPI, the doped optical fiber was mounted onto two fiber holders and aligned with the camera and laser beam by the 3-axis motorized platform. After adjusting the laser beam power to $342 \mu \mathrm{W}$ (measured before the microscope objective), the optical fiber was moved transversally in the plane perpendicular to the laser beam at a constant velocity of $0.1 \mathrm{~mm} / \mathrm{s}$, changing the core refractive index through a length, $\Delta x$, of $35 \mu \mathrm{m}$ and creating the first IFPI's mirror. Then, after blocking the laser beam with a shutter and moving the optical fiber longitudinally by a length, L, of $300 \mu \mathrm{m}$, the second IFPI mirror was inscribed. The final step was to change the refractive index along the optical fiber core comprised between the two mirrors. This was accomplished by positioning the laser beam focus on the center of the first mirror and moving longitudinally the optical fiber, at a velocity of $0.1 \mathrm{~mm} / \mathrm{s}$, until reaching the second mirror (Fig. 1(b)). By inserting red light into the optical fiber, the final cavity is illuminated and possible to be visualize at microscope (Fig. 1(d)). The final IFPI reflected optical spectrum is presented in Fig. 2.

\subsection{Fiber Bragg grating inscription}

The FBG inscription in the doped optical fiber started by placing the 


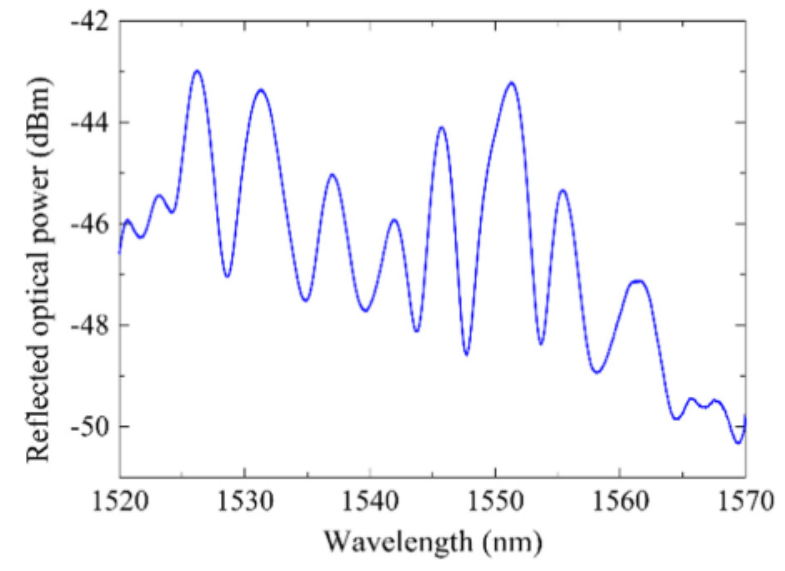

Fig. 2. Reflected optical spectrum of the inscribed IFPI.

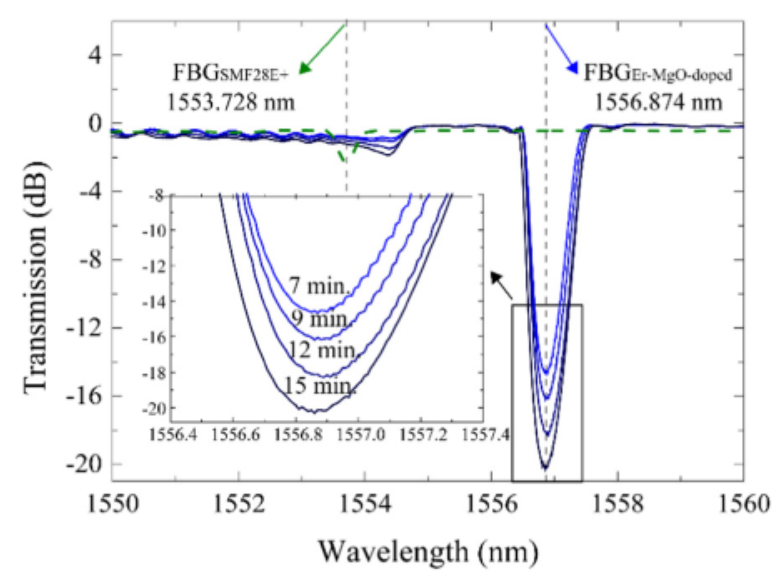

Fig. 3. Optical spectrum obtained in transmission of the FBGs inscribed in the MgO-doped fiber (blue solid lines) and SMF28E + (green dashed line). The vertical dot lines represent the dip central wavelength. The zoom-in shows the dip amplitude at different inscription times: for 7, 9, 12 and $15 \mathrm{~min}$. (For interpretation of the references to colour in this figure legend, the reader is referred to the web version of this article.)

fiber between two fiber holders, adjusting the region of interest to be at the laser beam path. Then, a phase mask designed for the laser wavelength (pitch $=1072 \mathrm{~nm}$ ) was placed in direct contact with the stripped optical fiber, maximizing the grating inscription physical length and, therefore, its inscription efficiency. Finalized the alignment procedures, the femtosecond laser was turned on and its beam (diameter of $\sim 7 \mathrm{~mm}$ ) focused by a convex cylindrical lens onto the fiber core. The laser power was adjusted so it had a value of, approximately, $245 \mathrm{~mW}$ right before the lens. This power value was chosen to maximize the efficiency of the FBG inscription process, without compromising the phase mask integrity. A time of $15 \mathrm{~min}$ was selected, resulting in a final grating reflectivity of $99 \%$ (dip amplitude in transmission of $\sim 19.7 \mathrm{~dB}$ ) and a Bragg wavelength $\left(\lambda_{\text {Bragg }}\right)$ of $1556.874 \mathrm{~nm}$ (Fig. 3, blue line).

As a term of comparison, an FBG was also recorded in a standard silica optical fiber (SMF28E + from Corning), using the exact same inscribing parameters. The resulted FBG presents a much lower reflectivity (about $32 \%$ ) and a $\lambda_{\text {Bragg }}$ of $1553.728 \mathrm{~nm}$ (Fig. 3, green dashed line). The difference between the Bragg wavelengths is due to the higher refractive index imposed by the dopants of the doped fiber. These results show that, for the same fabrications conditions, the FBGs inscribed in the doped optical fiber grows much faster than the gratings inscribed in standard fibers (for half the inscription time, $\sim 7 \mathrm{~min}$, the first FBG has already $96 \%$ of reflectivity). These reflectivity differences between both FBGs could be ascribed to both $\mathrm{Er}^{3+}$ ions, which has a small absorption near $796 \mathrm{~nm}$ (within the range of the output (a)
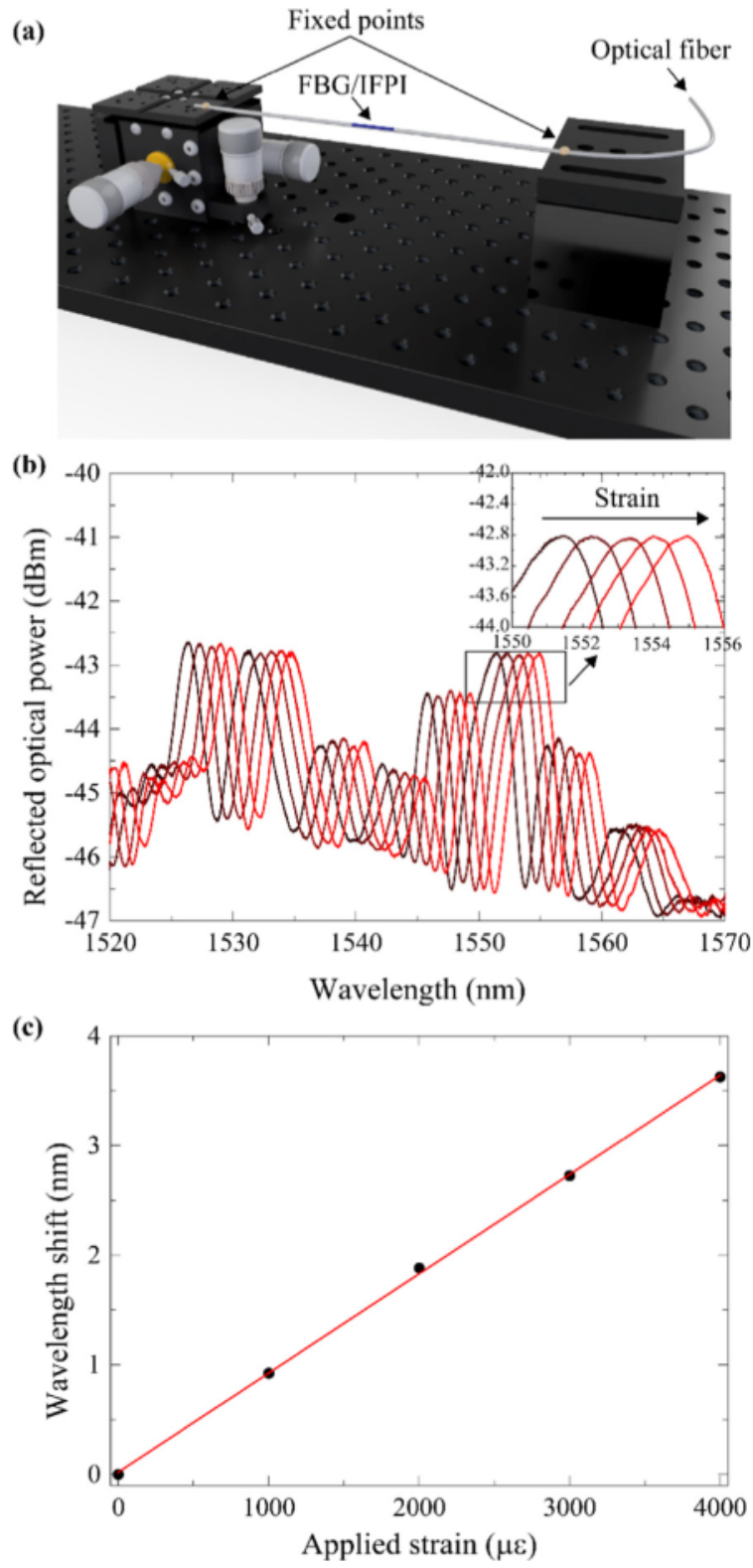

Fig. 4. (a) Schematic representation of the setup used in the strain characterization. (b) IFPI spectrum evolution with increasing strain. (c) Peak wavelength shift with applied strain. The black filled dots represent the mean values between the increasing and decreasing strain steps. The linear fit to the data is represented by the red line. (For interpretation of the references to colour in this figure legend, the reader is referred to the web version of this article.)

wavelength of the laser used) [14], and the high backscattering provided by the MgO NPs.

\section{IFPI and FBG characterization}

A thermal and strain characterization were performed to assess the devices responses to temperature and strain. For easiness of analyses, the reflected spectrum shifts of both devices were recorded by an optical interrogator (mentioned above).

\subsection{Strain characterization}

In the strain characterization, both FBG and IFPI fibers were stripped and fixed by a cyanoacrylate adhesive in between a 3-axis translation stage and a fixed base mount (see Fig. 4(a)). After completed 
Table 2

FBG and FPI characterization fitting parameters.

\begin{tabular}{llll}
\hline Characterization & Sensor & Sensitivity & Adj. R-Square \\
\hline \multirow{2}{*}{ Strain } & FBG & $0.85 \pm 0.02 \mathrm{pm} / \mu \varepsilon$ & 0.994 \\
& IFPI & $0.91 \pm 0.01 \mathrm{pm} / \mu \varepsilon$ & 0.999 \\
Temperature & FBG & $12.7 \pm 0.3 \mathrm{pm} /{ }^{\circ} \mathrm{C}$ & 0.995 \\
& IFPI & $10.2 \pm 0.5 \mathrm{pm} /{ }^{\circ} \mathrm{C}$ & 0.999 \\
\hline
\end{tabular}

the adhesive curing, the optical fibers were stretched by steps of $1 \mu \mathrm{m}$, until reaching strain values of 4000 and $5000 \mu \varepsilon$ for the IFPI and FBG, respectively.

To characterize the IFPI strain sensitivity, all peaks of the IFPI were analyzed, showing a very similar behavior between them. To avoid redundancy, we chose to present only the central wavelength shift of the 5th peak (Fig. 4(b)). As it is depicted in Fig. 4(c), the IFPI shows a linear response to the mean values between the applied increasing and decreasing strain cycles. Its sensitivity value to strain was attained by applying a linear fit to the data, which resulted in a value of $0.91 \pm 0.01 \mathrm{pm} / \mu \varepsilon$ (Table 2). Regarding the FBG strain sensitivity, its peak wavelength shift was also recorded and analyzed the mean value between the increasing and decreasing strain steps (see Fig. 5(a)). From the applied linear fit (Fig. 5(b)), the strain sensitivity value of $0.85 \pm 0.02 \mathrm{pm} / \mu \varepsilon$ was obtained (Table 2 ). These values of strain sensitivity for both devices are very close to already reported values for FBGs and FPIs fabricated in silica optical fibers [15-18]. However, the slightly lower sensitivity values could be related to intrinsic structural
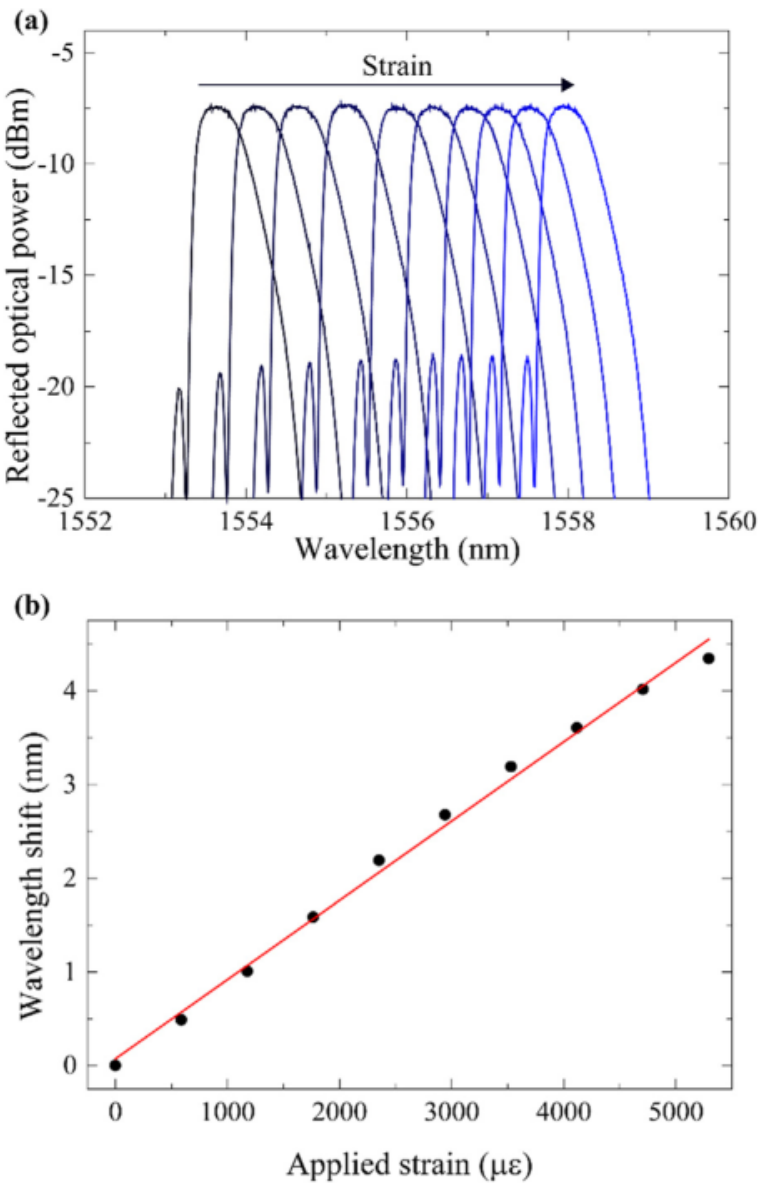

Fig. 5. (a) FBG spectrum evolution with strain. (b) Central peak wavelength shift with applied strain. The black filled dots represent the mean values between increasing and decreasing strain steps. The linear fit to the data is represented by the red line. (For interpretation of the references to colour in this figure legend, the reader is referred to the web version of this article.) (a)
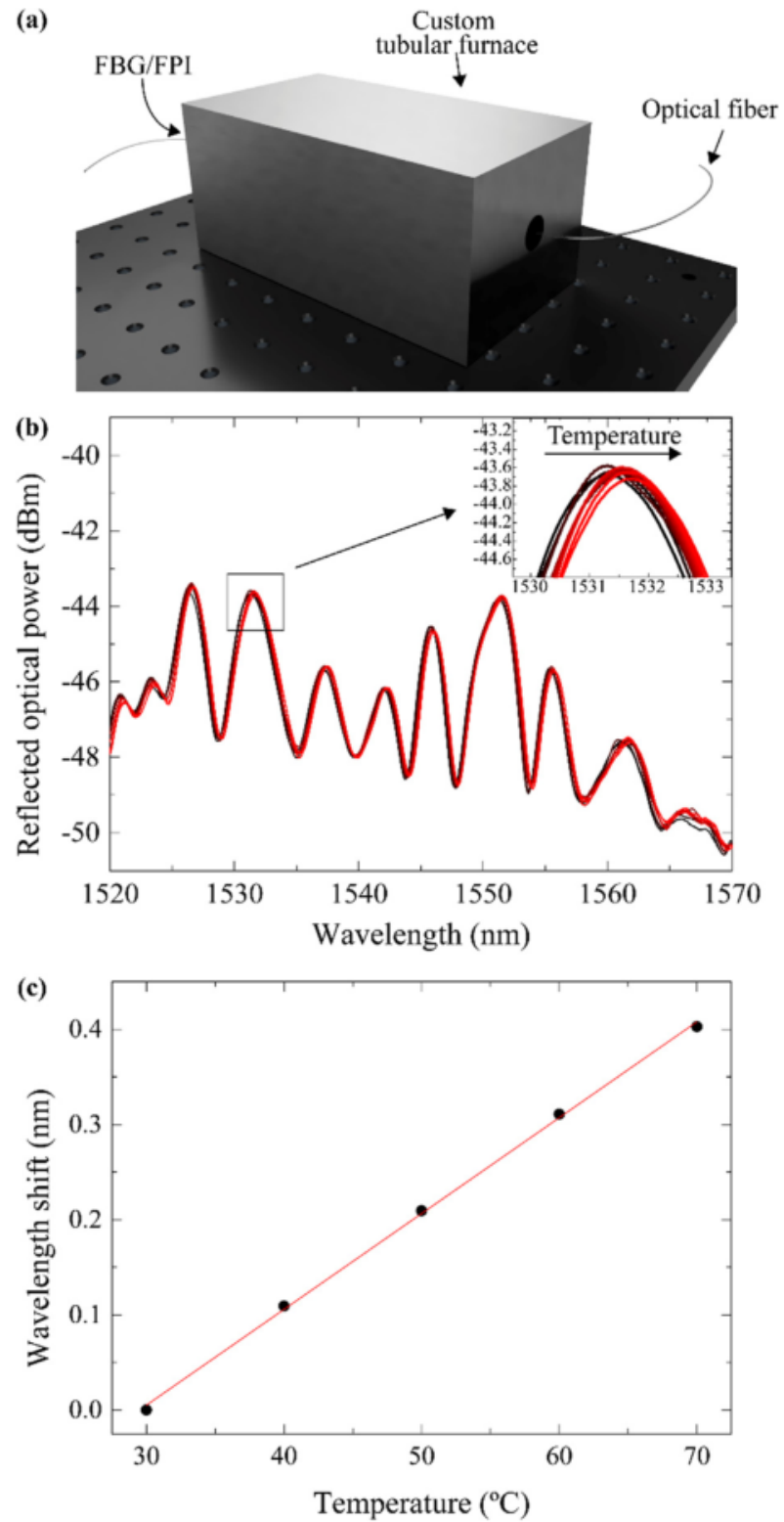

Fig. 6. (a) Schematic representation of the thermal charaterization setup. (b) IFPI spectrum evolution with temperature. (c) Peak wavelength shift with temperature. The black filled represent the mean values between the increasing and decreasing temperature steps. The linear fit to the data is represented by the red line. (For interpretation of the references to colour in this figure legend, the reader is referred to the web version of this article.)

modifications inserted in the silica matrix by the NPs and REs dopants.

\subsection{Thermal characterization}

To characterize the temperature response of both devices, a custom tubular furnace was used (resolution of $1{ }^{\circ} \mathrm{C}$, Fig. 6(a)). Both IFPI and FBG were placed inside the furnace without any applied strain, minimizing eventual misreading associated with cross-sensitivities.

The thermal regime adopted for the IFPI consisted on applying different temperature steps of $10 \mathrm{~min}$ each, ranging from $30^{\circ} \mathrm{C}$ to $70^{\circ} \mathrm{C}$. In this case, the analyzed peak was the one depicted in Fig. 6(b). From the linear fit applied to the mean values between increasing and decreasing temperature data (Fig. 6(c)), a temperature sensitivity of $10.2 \pm 0.5 \mathrm{pm} /{ }^{\circ} \mathrm{C}$ was obtained (Table 2).

Regarding the FBG thermal characterization, the setup and procedures used were the same as the IFPI, with a temperature range of 

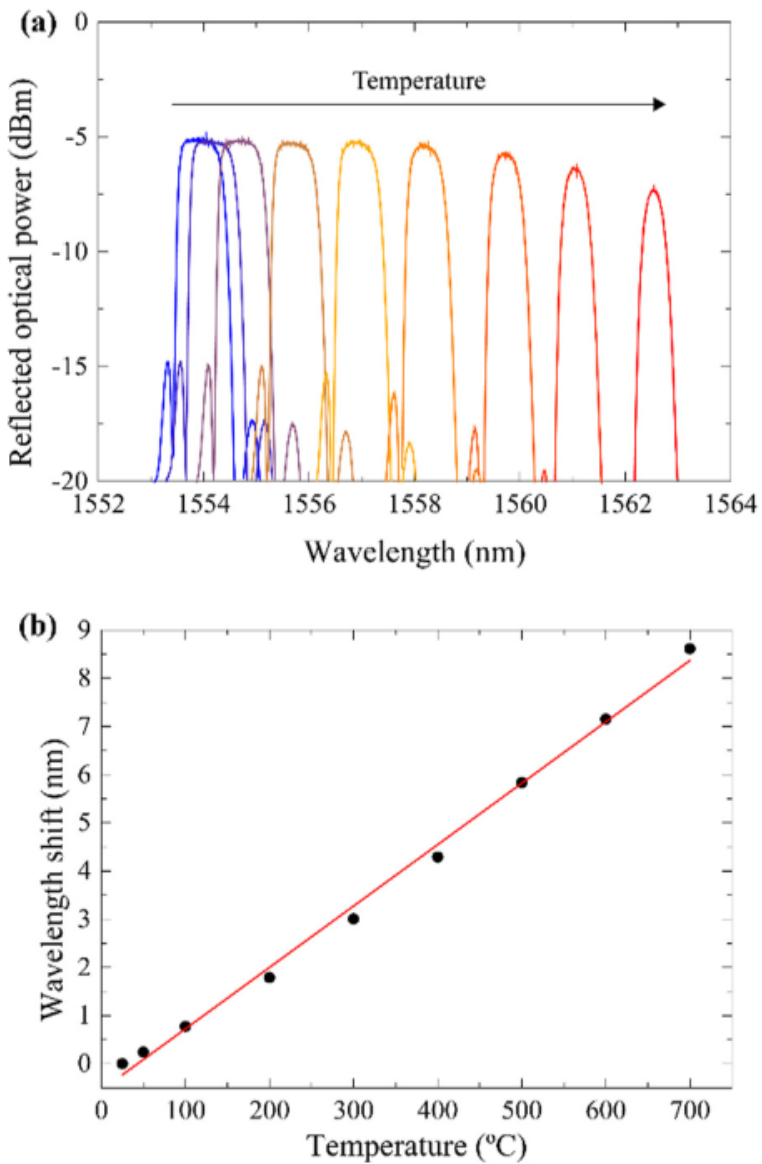

Fig. 7. (a) FBG spectrum for different temperatures, ranging from 25 up-to $700{ }^{\circ} \mathrm{C}$. (b) Peak's wavelength shift in function of applied temperature. The black filled represent the mean values between the increasing and decreasing temperature steps. The linear fit to the data is represented by the red line. (For interpretation of the references to colour in this figure legend, the reader is referred to the web version of this article.)

$25-700{ }^{\circ} \mathrm{C}$. This different applied temperature range is due to the possible different applications for each device. In the FBG case, if the purpose is to build a laser, it is important to test its performance at hightemperatures and assure reliability for low and high temperatures.

In Fig. 7(a) is presented the Bragg wavelength shift with temperature. It is clear that a red shift occurs with increasing temperature, and the peak's amplitude decreases only $2 \mathrm{~dB}$ at $700^{\circ} \mathrm{C}$. This decreasing in optical power amplitude is a characteristic of FBGs inscribed by both nano and femtosecond laser (NIR or UV), if they are not submitted to any pre-annealing treatments $[19,20]$. However, we can assume that the inscribed FBG could withstand higher temperatures than conventional ones, due to the enhanced photo-inscription mechanism imposed by the NPs present in the optical fiber, resulting in much more stable gratings.

The Bragg wavelength shift with temperature was recorded and a linear fit applied to the data (Fig. 7(b)). The achieved temperature sensitivity of the FBG was $12.7 \pm 0.3 \mathrm{pm} /{ }^{\circ} \mathrm{C}$ (Table 2), which is in accordance with already reported works $[21,22]$.

\section{Conclusions}

In this paper, we report on the inscription of an intrinsic Fabry-Pérot interferometer and a fiber Bragg grating in a silica optical fiber doped with $\mathrm{Er}^{3+}$ and $\mathrm{MgO}$ nanoparticles, by means of a NIR femtosecond laser. The thermal and strain characterizations of both devices revealed sensitivities values similar to already reported works, which validate the use of these devices as sensors. Moreover, the doped optical fiber exhibits excellent inscription performance, when compared to FBGs inscribed in standard silica optical fibers. These results show that, for the same fabrications conditions, the FBGs inscribed in the Er-MgOdoped optical fiber grows much faster than the gratings inscribed in standard fibers, achieving higher strengths (32\% for SMF28E + vs. $99 \%$ for $\mathrm{Er}$-MgO-doped optical fiber). This fact allied with the high-temperature performance, supports the use of this type of fiber on developing new optoelectronic devices, especially high-temperature sensors. Despite the fact that the IFPI's fabrication method and performance are in accordance with already reported works, by inscribing it in an Er$\mathrm{MgO}$-doped optical fiber we could develop optoelectronic devices (such as optical filters, amplifiers and lasers) with much higher quality and efficiency $[23,24]$.

\section{Funding}

This work is funded by FCT/MEC through national funds, through FCT - Fundação para a Ciência e a Tecnologia, I.P., in the scope of the framework contract foreseen in the numbers 4,5 and 6 of the article 23, of the Decree-Law 57/2016, of August 29, changed by Law 57/2017, of July 19, and when applicable co-funded by FEDER - PT2020 partnership agreement under the project UID/CTM/50025/2019. Tiago Paixão acknowledges Fundação para a Ciência e Tecnologia (FCT) for the grant with the reference PD/BD/128265/2016. This work was also funded by: ORAU program at Nazarbayev University through grants LIFESTART (PI: Daniele Tosi) and FOSTHER (PI: Carlo Molardi); ANR project NanoSlim (ANR-17-17-CE08-0002).

\section{Declaration of Competing Interest}

The authors declare that they have no known competing financial interests or personal relationships that could have appeared to influence the work reported in this paper.

\section{References}

[1] W. Blanc, V. Mauroy, L. Nguyen, B.N.S. Bhaktha, P. Sebbah, B.P. Pal, B. Dussardier, Fabrication of rare earth-doped transparent glass ceramic optical fibers by modified chemical vapor deposition, J. Am. Ceram. Soc. 94 (2011) 2315-2318.

[2] S.V. Firstov, S.V. Alyshev, K.E. Riumkin, V.F. Khopin, A.N. Guryanov, M.A. Melkumov, E.M. Dianov, A 23-dB bismuth-doped optical fiber amplifier for a 1700-nm band, Sci. Rep. 6 (2016).

[3] S. Yin, P.B. Ruffin, F.T.S. Yu, Fiber Optics Sensors, second ed.,, CRC Press, 2008.

[4] D.A. Krohn, T.W. MacDougall, A. Mendez, Fiber Optic Sensors: Fundamentals and Applications, fourth ed., SPIE Press Book, 2015.

[5] M.M. Werneck, R.C.S.B. Allil, B.A. Ribeiro, F.V.B. de Nazaré, A Guide to Fiber Bragg Grating Sensors, Current Trends in Short- and Long-period Fiber Gratings", Christian Cuadrado-Laborde, IntechOpen, 2013.

[6] T. Paixão, F. Araújo, P. Antunes, Highly sensitive fiber optic temperature and strain sensor based on an intrinsic Fabry-Perot interferometer fabricated by a femtosecond laser, Opt. Lett. 44 (2019).

[7] J. Ma, Y. Zhou, X. Bai, K. Chen, B.O. Guan, High-sensitivity and fast-response fibertip Fabry-Pérot hydrogen sensor with suspended palladium-decorated graphene, Nanoscale (2019) 11.

[8] J. Xia, F. Wang, H. Luo, Q. Wang, S. Xiong, A magnetic field sensor based on a magnetic fluid-filled fp.fbg structure, Sensors 16 (2016) 620.

[9] Q. Liu, Z.L. Ran, Y.J. Rao, S.C. Luo, H.Q. Yang, Y. Huang, Higly integrated FP/FBG sensor for simultaneaous measurement of high temperatre and strain, IEEE Photonics Technol. Lett. 26 (2014) 17.

[10] D. Grobnic, S.J. Mihailov, R.B. Walker, C.W. Smelser, C. Lafond, A. Croteau, Bragg gratings made with a femtosecond laser in heavily doped Er-Yb phosphate glass fiber, IEEE Photon. Technol. Lett. 19 (2007) 12.

[11] E. Wikszak, J. Thomas, J. Burghoff, B. Ortaç, J. Limpert, S. Nolte, Erbium fiber laser based on intracore femtosecond-written fiber Bragg grating, Opt. Lett. 31 (2006) 16.

[12] S.J. Mihailov, C. Hnatovsky, D. Grobnic, Novel Type II Bragg Grating structures in silica fibers using femtosecond lasers and phase masks, J. Lightwave Technol. 7 (2019) 11.

[13] W. Blanc, B. Dussardier, Formation and applications of nanoparticles in silica optical fibers, J. Opt. 45 (2016) 3.

[14] Y. Shen, Y. Oiu, B. Wu, W. Zhao, S. Chen, T. Sun, K.T.V. Grattan, Short cavity single frequency fiber laser for in-situ sensing applications over a wide temperature range, Opt. Express 15 (2007) 2. 
[15] H.N. Li, D.S. Li, G.B. Song, Recent applications of fiber optic sensors to health monitoring in civil engineering, Eng. Struct. 26 (2004).

[16] M. Nascimento, S. Novais, M.S. Ding, M.S. Ferreira, S. Koch, S. Passerini, J.L. Pinto, Internal strain and temperature discrimination with optical fiber hybrid sensors in Li-ion batteries, J. Power Sour. (2018).

[17] C.E. Campanella, A. Cuccovillo, C. Campanella, A. Yurt, V.M.N. Passaro, Fibre Bragg Grating based strain sensors: review of technology and applications, Sensors 18 (2018) 3115.

[18] D. Kinet, P. Mégret, K.W. Goossen, L. Oiu, D. Heider, C. Caucheteur, Fiber bragg grating sensors toward structural health monitoring in composite materials: chal lenges and solutions, Sensors 14 (2014).

[19] T. Erdogan, V. Mizrahi, P.J. Lemaire, D. Monroe, Decay of ultraviolet-induced fiber Bragg gratings, J. Appl. Phys. 76 (1994) 73.
[20] A. Martinez, I.Y. Khrushchev, I. Bennion, Thermal properties of fibre Bragg gratings incribed point-by-point by infrared femtosecond laser, Electron, Lett. 41 (2005) 4.

[21] E. Schena, D. Tosi, P. Saccomandi, E. Lewis, T. Kim, Fiber optic sensors for temperature monitoring during thermal treatments: an overview, Sensors 16 (2016).

[22] R. Mahakud, J. Kumar, O. Prakash, S.K. Dizit, Study of the nonuniform behaviour of temperature sensitivity in bare and embedded fiber Bragg gratings: experimental results and analysis, Appl. Opt. 52 (2013) 31.

[23] P. Chen, X. Shu, Refractive-index-modified-dot Fabry-Perot fiber probe fabricated by femtosecond laser for high-temperature sensing, Opt. Express 26 (2018) 5 .

[24] Y. Zhang, J. Huang, X. Lan, L. Yuan, H. Xiao, Simultaneous measurement of temperature and pressure with cascaded extrinsic Fabry-Perot interferometer and in trinsic Fabry-Perot interferometer sensors, Opt. Eng. 53 (2014) 6. 